\title{
MEMPELAJARI KONSEP MATEMATIKA YANG TERSEMBUNYI PADA TABEL PERKALIAN MELALUI SPREADSHEET
}

\author{
Oleh \\ I Nyoman Sukajaya, \\ Jurusan Pendidikan Matematika, FMIPA, UNDIKSHA
}

\begin{abstract}
Abstrak
Tulisan ini menyajikan sejumlah aktivitas belajar yang dapat dibelajarkan melalui tabel perkalian yang dikembangkan melalui spreadsheet. Aktivitas-aktivitas ini dikembangkan menggunakan fitur perangkat lunak seperti: formula kondisional, format kondisional, fungsi lojik, iterasi dalam penghitungan dan scroll bar. Beragam ide-ide matematika yang lebih kompleks dapat dibelajarkan melalui alat bantu ini yang memungkinkan guru dapat memahami ide-ide lebih mudah seperti: tabel perkalian sebagai spreadsheet, mengembangkan definisi matematis melalui format kondisional, struktur iteratif dalam tabel perkalian dan sifat habis dibagi. Pendekatan yang menekankan pada pengalaman berbasiskan spreadsheet memudahkan guru memaknai generalisasi serta mengapresiasi kreasi penambahan sejumlah konsep dengan tingkat abstraksi yang juga meningkat.
\end{abstract}

Kata kunci: $\quad$ Tabel perkalian, kurikulum matematika tersembunyi, pendidikan guru matematika

\begin{abstract}
This paper reveals a number of learning activities emerging from a spreadsheet generated multiplication table. These activities are made possible by using such features of the software as conditional formula, conditional formatting, logical functions, calculation through iteration, and scroll bars. Many complex mathematical ideas can become embedded in this powerful software tool enabling the teachers to understand these ideas such as: the multiplication tabel as a spreadsheet, Conditional formatting as a practice in developing mathematical definition, representing the multiplication table as an iterative Structure, Counting numbers with special properties in the multiplication table. Such an approach, when enhanced by the use of spreadsheets, makes it easier for the teachers to grasp the meanings of generalization and to appreciate the creation of an increasing number of general concepts on higher levels of abstraction.
\end{abstract}

Key words: multiplication table, hidden mathematics curriculum, mathematics teacher education

\section{LATAR BELAKANG}

Mempelajari Konsep Matematika yang Tersembunyi..............(I Nyoman Sukajaya) 
Semua orang yang sempat mengenyam sistem pendidikan akan setuju bahwasannya salah satu materi yang sempat dipelajari sejak di jenjang pendidikan dasar adalah operasi perkalian. Pembelajaran operasi ini disajikan melalui fakta perkalian bilangan bulat yang dikemas dalam bentuk tabel perkalian. Lebih jauh lagi yang mungkin masih dapat diingat adalah mekanisme bagaimana operasi ini dibelajarkan di sekolah. Fakta-fakta ini cenderung disajikan sedemikian rupa yang menyaratkan pebelajar mampu mememorisi fakta. Ekstrimnya, hampir tidak pernah guru maupun siswa mencermati apakah sesungguhnya ada konsep matematika yang lebih kompleks termuat di dalam fakta tersebut. Kondisi ini cenderung berlarut-larut dibawa sampai ke jenjang pendidikan yang lebih tinggi. Dampak yang terlihat, orang hanya memandang tabel perkalian tidak lebih dari sederetan bilangan bulat yang disusun sedemikian rupa sebagai produk perkalian bilangan bulat komponennya.

Realitas mekanisme belajar seperti di atas dalam kerangka kurikulum hiddenmathematics tidak dibenarkan sebagaimana diargumentasikan dalam Conference Board of the Mathematical Sciences yakni pentingnya memahami lingkungan belajar yang memungkinkan guru "to create meaning for what many had only committed to memory but never really understood". Sudut pandang kurikulum hidden-mathematics sejalan dengan pandangan Bruner dan stewart yang menyatakan bahwa kurikulum matematika sekolah tidak semestinya terbatas pada ide-ide atau konsep formal yang terakses sebagai gagasan atau konsep diri saja. Kerangka kurikulum ini didasarkan pada opini bahwa tugas-tugas rutin matematika apabila dieksplorasi menembus batas-batas kurikulum tradisional potensial dijadikan jendela ide yang sangat luas guna meningkatkan keterampilan dasar matematika. Potensi ini signifikan dapat diwujudkan dengan adanya dukungan kemajuan di bidang teknologi spreadsheet khususnya fitur visualisasinya serta fitur lainnya.

NCTM menuliskan: "Mathematics is one of the greatest cultural and intellectual achievements of human-kind, and citizens should develop an appreciation and understanding of that achievement, including its aesthetic and even recreational aspects". (NCTM, 2000, 4). Representasi kekuatan matematika tampak pada dua sisi. Pertama, matematika merupakan paradigma sense-making, melalui matematika orang mampu menganalisis, mengorganisir, dan memaknai lingkungannya. Kedua, Model atau representasi matematika selanjutnya dapat dikembangkan ke tahapan analisa

JPTK, UNDIKSHA, Vol. 7, No. 1, Januari 2010 : 1 - 12 
lanjutan dan mengarahkan pembuatan keputusan atau perencanaan. Integrasi keduanya yakni matematika dengan lingkungan sekitar memberikan kekuatan serta kegunaan dari matematika. Keindahan utama dari matematika terletak pada kegunaanya bagi orang untuk mengobservasi, menginterpretasi dan mengubah lingkungan di mana mereka hidup. Dengan kata sederhana, matematika merupakan alat yang menjadikan orangorang mampu berinteraksi dengan lingkungan alami dan sosial.

Begitu indahnya matematika serta perkembangan fitur spreadsheet yang potensi mendukung peningkatan pemahaman ide maupun konsep terus memotivasi pakar-pakar matematika merancang kurikulum matematika yang menyiapkan siswa mampu belajar berkelanjutan serta mampu menyelesaikan masalah dalam beragam situasi. Salah satu implementasinya dapat dilihat bahwa standar pembelajaran matematika yang difokuskan pada konsep yang berorientasi pada aktivitas pemecahan masalah. Implementasi lain yang dijuga disarankan adalah memanfaatkan kerangka kurikulum matematika tersembunyi (Abramovich dan Brouwer, 2003, 81-94), khususnya pemanfaatan fitur visualisasi spreadsheet. Melalui pengintegrasian spreadsheet dan mediasi pedagogi yang tepat, sejumlah ide matematika yang kompleks dapat disajikan melalui perangkat lunak yang memungkinkan orang memahami ide tersebut.

Berdasarkan paparan di atas, sajian berikut memaparkan kajian struktur yang potensial dikembangkan dari tabel perkalian dengan memanfaatkan teknologi spreadsheet. Struktur yang dimaksud di antaranya adalah: tabel perkalian sebagai spreadsheet, latihan mengembangkan definisi matematis melalui format kondisional, tabel perkalian sebagai struktur iteratif serta sifat habis dibagi dalam tabel perkalian.

\section{PEMBAHASAN}

\subsection{Tabel Perkalian}

Salah satu materi matematika yang dibelajarkan di sekolah adalah operasi bilangan beserta sifat-sifatnya. Operasi yang dibelajarkan di antaranya adalah perkalian dua bilangan atau lebih. Di jenjang sekolah dasar, materi ini dibelajarkan melalui tabel perkalian. Lebih jauh, penggunaan tabel perkalian dibelajarkan melalui pembelajaran tradisional yakni mengajak siswa melihat tabel hanya sebatas sebagai alat bantu untuk mengecek apakah hasil dari operasi perkalian yang dikerjakan sudah benar atau belum. 
Belum ada upaya melihat lebih jauh lagi apa yang mugkin pula dibelajarkan melalui pemanfaatan tabel perkalian.

Tabel perkalian menurut kerangka kurikulum hidden-mathematics seperti yang dikemukakan oleh Abramovich sesungguhnya mengandung banyak aktivitas konseptual yang dapat dimanfaatkan untuk memperkaya pembelajaran matematika sekolah. Aktivitas konseptual yang dimaksud didukung oleh pemanfaatan sejumlah fitur lanjutan spreadsheet. Melalui pemanfaatan perangkat lunak memungkinkan mengonstruksi lingkungan belajar yang dinamis untuk menemukan sejumlah sifat-sifat penting bilangan buat yang tersembunyi di balik tabel perkalian statik. Steffe dalam Abramovich melabeli lingkungan belajar yang demikian sebagai lingkungan belajar yang potensial "possible learning environments (PLE)" yang bermakna bahwa rancangan aktivitas pembelajaran hendaknya mampu melampaui harapan-harapan siswa dalam pembelajaran secara tradisional.

\section{1.a Tabel Perkalian sebagai Spreadsheet}

Secara struktur, tabel perkalian terdiri dari perkalian dua bilangan positif pada rentangan yang telah ditetapkan(Abramovich, 2005,5). Tabel ini selain sebagai alat untuk pembelajaran operasi perkalian juga dapat digunakan mengenalkan berbagai konsep-konsep yang dibela-jarkan di matematika sekolah. Pertama, dengan menggunakan tabel ini dapat dibelajarkan konsep-konsep seperti hukum komutatif, hukum distributif perkalian terhadap penjumlahan, pemfaktoran, sifat habis dibagi dan simetri. Lebih jauh, terdapat banyak konsep yang menarik di antara bilangan-bilangan bulat positif yang secara implisit tersirat dalam tabel perkalian. Konsep-konsep tersebut meliputi: bilangan-bilangan segitiga, formula penjumlahan, teknik menghitung, serta pembuktian induksi matematika.

Untuk melihat konsep-konsep yang tersurat di dalam tabel perkalian maka dibutuhkan aktivitas komputasi yang dipadukan dengan tugas-tugas. Aktivitas komputasi ini menggunakan tabel perkalian yang dikembangkan melalui spreadsheet seperti tampak pada gambar 1.

JPTK, UNDIKSHA, Vol. 7, No. 1, Januari 2010 : 1 - 12 


\begin{tabular}{|c|c|c|c|c|c|c|c|c|c|c|c|c|}
\hline A & \multicolumn{2}{|c|}{ B } & C & D & $\mathrm{E}$ & $F$ & G & $\mathrm{H}$ & 1 & J & K & L \\
\hline & & & \multicolumn{10}{|c|}{ TABEL PERKALIAN } \\
\hline & \multirow[b]{2}{*}{ 스 } & & 1 & 2 & 3 & 4 & 5 & 6 & 7 & 8 & 9 & 10 \\
\hline & & 1 & 1 & 2 & 3 & 4 & 5 & 6 & 7 & 8 & 9 & 10 \\
\hline & \multirow{2}{*}{ 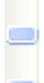 } & 2 & 2 & 4 & 6 & 8 & 10 & 12 & 14 & 16 & 18 & 20 \\
\hline & & 3 & 3 & 6 & 9 & 12 & 15 & 18 & 21 & 24 & 27 & 30 \\
\hline & \multirow[t]{7}{*}{$\underline{v}$} & 4 & 4 & 8 & 12 & 16 & 20 & 24 & 28 & 32 & 36 & 40 \\
\hline & & 5 & 5 & 10 & 15 & 20 & 25 & 30 & 35 & 40 & 45 & 50 \\
\hline & & 6 & 6 & 12 & 18 & 24 & 30 & 36 & 42 & 48 & 54 & 60 \\
\hline & & 7 & 7 & 14 & 21 & 28 & 35 & 42 & 49 & 56 & 63 & 70 \\
\hline & & 8 & 8 & 16 & 24 & 32 & 40 & 48 & 56 & 64 & 72 & 80 \\
\hline & & 9 & 9 & 18 & 27 & 36 & 45 & 54 & 63 & 72 & 81 & 90 \\
\hline & & 10 & 10 & 20 & 30 & 40 & 50 & 60 & 70 & 80 & 90 & 100 \\
\hline
\end{tabular}

Gambar 1. Spreadsheet Tabel Perkalian

Untuk menghasilkan spreadsheet seperti pada gambar1, kolom B dan baris 2 diisi bilangan bulat positif yang dimulai dari 1 dan selanjutnya disebut sebagai komponen $x$ dan y. Penamaan sel di spreadsheet office 2007 dikerjakan melalui perintah Define Name - dari submenu Formulas . Pada kotak isian Name: dari jendela Edit Name ketik nama sel $(x)$ dan range sel yang diacu diisikan pada kotak isian $\underline{\text { Refers to. }}$ Langkah yang serupa dilakukan untuk menamai sel $(y)$.

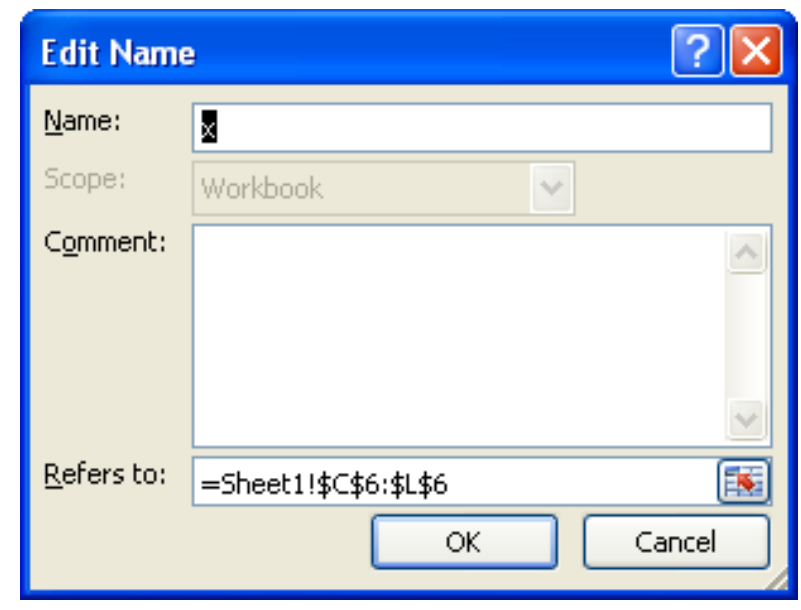

Gambar 2. Jendela Edit Name

Rentangan nilai tabel perkalian tergantung dari ukuran tabel ( $n$ ) yang ditetapkan melalui objek Scroll Bar. Pilih ikon 뵈 (Scroll Bar ActiveX Contol) kemudian letakan pada spreadsheet. Klik kanan pada objek Scroll Bar kemudian pilih sub menu 
Properties. Pada jendela properties tentukan rentangan nilai (minimum dan maksimum) yang diijinkan serta alamat sel (A3) yang akan mencatat nilai yang dipilih. Sel C2 dan B3 masing-masing diisi nilai 1 dan di sel D2 dan B4 masing-masing diberikan formula: =IF $(\mathbf{C} \$ 2<n ; \mathbf{C} \$ 2+1 ; "$ ") dan =IF $(\$ B 3<n$; $\$$ B3+1; " "). Salin masing-masing formula sepanjang baris 2 dan turun pada kolom B. Di sel C3 berikan formula: =IF(OR(x =" "; $\mathbf{y}="$ "); " "; $\left.\mathbf{x}^{*} \mathbf{y}\right)$ serta salin formula ini sesuai ukuran tabel. Keseluruhan perintah tersebut akan menghasilkan larik bilangan yang disebut tabel perkalian (gambar 1).

\section{1.b Latihan Mengembangkan Definisi Matematis Melalui Format Kondisional}

Format kondisional merupakan kemampuan spreadsheet modern yang memungkinkan format otomatis sel berdasarkan nilai terkininya. Apabila range sel yang memiliki nilai berbeda-beda mesti diformat sama maka pendefinisian kondisi tidak didasarkan pada nilai sel tertentu tetapi pada pola umum yang mewakili range nilai tersebut. Seperti pada gambar 1 terlihat bahwa sel yang jumlah komponen $x$ dan $y$-nya kurang dari (ukuran tabel +1 ) diformat dengan warna hijau, sama dengan (ukuran tabel +1 ) diformat dengan warna putih dan lebih dari (ukuran tabel +1 ) diformat dengan warna kuning. Berdasarkan pola tersebut diperoleh formula untuk menampilkan tabel perkalian dengan format kondisional seperti gambar 1 sebagai berikut.

kondisi 1 formulanya: $=\mathbf{C} \mathbf{2}+\mathbf{\$ B 3}<\boldsymbol{n}+\mathbf{1}$ format warna hijau

kondisi 2 formulanya: $=\mathbf{C} \$ \mathbf{2}+\$ \mathbf{B 3}>\boldsymbol{n}+\mathbf{1}$ format warna kuning

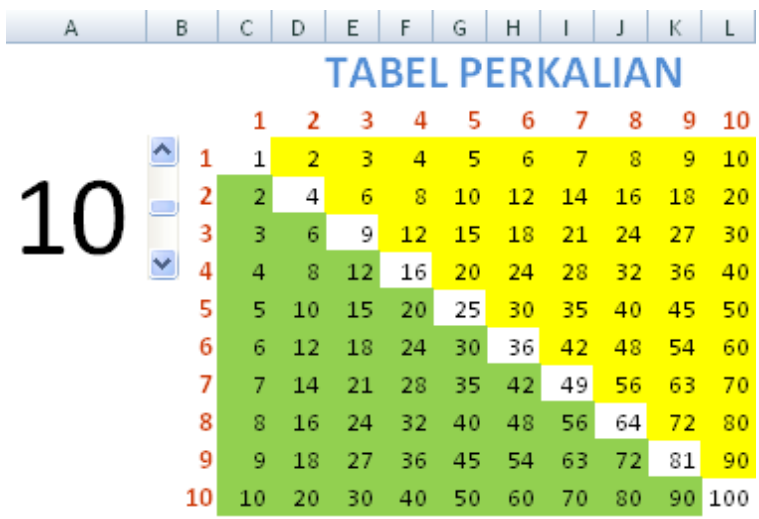

Gambar 3. Format Kondisional Simetris

Formula untuk menghasilkan gambar 3 memiliki kompleksitas lebih dibandingkan dengan gambar 1. Setiap sel di atas sel diagonal (warna putih) memiliki komponen $x$ 
yang kurang dari komponen $y$. Formula ini berganti untuk sel-sel di bawah sel diagonal. Formula untuk menghasilkan gambar 3 adalah sebagai berikut.

kondisi 1 formulanya: =AND $(\mathbf{C} \$ 2>\$ B 3, \mathbf{C} \$ 2<=\mathbf{n}, \$ B 3<=\mathbf{n})$ format warna kuning kondisi 2 formulanya: =AND $(\mathbf{C} \$ 2<\$ B 3, \mathbf{C} \$ 2<=\mathbf{n}, \$ B 3<=\mathbf{n})$ format warna hijau Formula ini dientrikan melaui jendela Edit Formatting Rule seperti pada gambar 4.

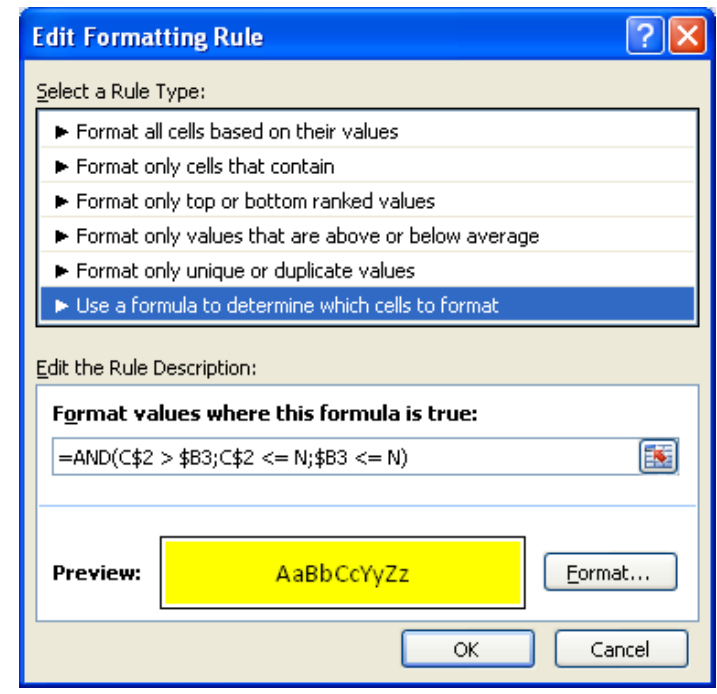

Gambar 4. Jendela Edit Formatting Rule

Kunci dari formula untuk tampilan gambar 3 adalah pelibatan peubah $n$ sehingga formatnya gayut terhadap ukuran tabel. Pada gambar 1 formulanya sudah otomatis melibatkan peubah $n$ sedangkan pada gambar 3 pelibatan peubah $n$ dikhususkan di dalam formula. Kondisi ini menjelaskan perlunya melibatkan operator AND dalam formula. Dengan cara seperti itu ditunjukan bahwa pemanfaatan spreadsheet moderen mampu menyajikan latihan untuk memahami dan mendemonstrasikan bagaimana sistem mampu mempersonifikasi definisi secara matematis.

\section{1.c Struktur Iteratif di Dalam Tabel Perkalian}

Selain konsep-konsep tersebut di atas, melalui tabel perkalian juga dapat dibelajarkan konsep diskrit. Fakta ini dapat dilihat mulai dari kolom kedua (kolom D dari hasil perkalian) yakni nilai sel pada kolom tersebut dapat dihasilkan dari nilai satu sel kolom di kirinya ditambahkan dengan nilai sel pada kolom pertama (kolom B). Demikian juga dengan nilai sel pada tabel hasil perkalian yang dimulai dari baris kedua 
(baris 4) nilainya dapat diperoleh dari nilai satu sel baris di atasnya diambahkan dengan nilai pada baris pertama.

Melalui fakta ini dapat diyakinkan konsep perkalian sebagai penjumlahan berulang, dimana setiap sel di dalam tabel perkalian merupakan hasil kali dua faktor dengan cara menambahkan berulang satu faktornya. Secara aljabar fakta ini dapat disajikan melalui masing-masing identitas: $\mathrm{xy}=(\mathrm{x}-1) \mathrm{y}+\mathrm{y}$ dan $x y=x(y-1)+x$. Dalam notasi formal, jika $\mathrm{P}(x, y)$ mewakili $x y$ maka $\mathrm{P}(x, y)$ dapat diekspresikan mengacu ke persamaan diferensial dua variabel sebagai berikut.

$$
\begin{aligned}
& \mathrm{P}(x, y)=\mathrm{P}(x-1, y)+y, \text { atau } \\
& \mathrm{P}(x, y)=\mathrm{P}(x, y-1)+x .
\end{aligned}
$$

yang memenuhi syarat batas $\mathrm{P}(1, y)=y$ dan $\mathrm{P}(x, 1)=x$. Beberapa identitas sederhana dapat dirumuskan, dibuktikan, kemudian diinterpretasikan menggunakan sifat-sifat operasi terkait.

$$
\begin{aligned}
& \mathrm{P}(x, y+m)=\mathrm{P}(x, y)+m y \\
& \mathrm{P}(x+m, y)=\mathrm{P}(x, y)+m x \\
& \mathrm{P}(x, y+m)=\mathrm{P}(x, y)+\mathrm{P}(x, \mathrm{~m}) \\
& \mathrm{P}(x+m, y)=\mathrm{P}(x, y)+\mathrm{P}(m, y)
\end{aligned}
$$

Penurunan dari salah satu identitas di atas (iii) dikerjakan sebagai berikut.

$$
\mathrm{P}(x, y+m)=\mathrm{P}(x, y)+m x
$$

Berdasarkan (i) maka (iii) dapat dituliskan menjadi:

$$
\begin{aligned}
& \mathrm{P}(x, y+m)=\mathrm{P}(x, y+m-1)+x \text { yang ekivalen dengan } \\
& \mathrm{P}(x, y+m)=\mathrm{P}(x, y+m-2)+x+x \\
& \mathrm{P}(x, y+m)=\mathrm{P}(x, y+m-3)+x+x+x \\
& =\mathrm{P}(x, y+m-(\mathrm{m}-1))+x+x+x+\ldots+x \\
& \underbrace{x+x+x+\ldots+x} \\
& (m-1) \text { suku } \\
& \downarrow \\
& (m-1) \cdot x \\
& =\mathrm{P}(x, y+m-\mathrm{m}))+(m-1) \cdot x+x \\
& \mathrm{P}(x, y+m)=\mathrm{P}(x, y))+m \cdot x
\end{aligned}
$$

JPTK, UNDIKSHA, Vol. 7, No. 1, Januari 2010 : 1 - 12 


\section{1.d Sifat Habis Dibagi dalam Tabel Perkalian}

Di dalam tabel perkalian berukuran $n \times n$ mungkin juga dihitung banyaknya bilangan yang memenuhi sifat tertentu. Sifat yang dimaksud misalnya adalah sifat habis dibagi. Kebutuhan ini dapat dibelajarkan dengan mengingatkan kembali syarat habis dibagi. Apabila diketahui sebuah bilangan misalnya num dibagi oleh faktor $f$ dapat dituliskan sebagai num $=f \times r+s$ dimana $r$ merupakan hasil bagi bulat num oleh faktor $f$ serta $s($ sisa $)=$ num $-(f \times r)($ Santos,2007,17). Berdasarkan ketentuan tersebut, sebuah bilangan num dikatakan habis dibagi $f$ apabila sisa dari pembagian bilangan num oleh faktor $f$ bernilai 0 . Dalam operasi aritmatika, operasi pembagian untuk menampilkan hasil bagi bulat menggunakan operator div sedangkan untuk menampilkan sisa menggunakan operator mod. Jadi untuk menentukan apakah sebuah bilangan (num) habis dibagi oleh faktor $f$ dapat diuji dengan melihat apakah operasi num $\bmod f=0$. Jika benar maka $f$ merupakan faktor dari num dan sebaliknya.

Di dalam spreadsheet, sifat habis dibagi dapat dibangun dengan menambahkan formula =IF(OR(x=" "; $\mathbf{y = " ~ " ) ; " ~ " ; ~ I F ( M O D ( x * y ; f a k t o r ) = 0 ; ~} \mathbf{x}^{*} \mathbf{y} ;$ " ")) ke sel C3. Salin isi sel C3 sesuai ukuran tabel perkalian. Dalam formula tersebut, parameter faktor ditentukan melalui Scroll Bar yang dihubungkan dengan sel A7. Tampilan spreadsheet tampak pada gambar 5 .

\begin{tabular}{|c|c|c|c|c|c|c|c|c|c|c|c|c|}
\hline A & I & 3 & C & D & $E$ & $\mathrm{~F}$ & G & $\mathrm{H}$ & I & J & K & $\mathrm{L}$ \\
\hline & & & \multicolumn{10}{|c|}{ Multiplication Table } \\
\hline & & & 1 & 2 & 3 & 4 & 5 & 6 & 7 & 8 & 9 & 10 \\
\hline & 스 & 1 & & 2 & & 4 & & 6 & & 8 & & 10 \\
\hline & 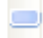 & 2 & 2 & 4 & 6 & 8 & 10 & 12 & 14 & 16 & 18 & 20 \\
\hline & $\checkmark$ & 3 & & 6 & & 12 & & 18 & & 24 & & 30 \\
\hline & & 4 & 4 & 8 & 12 & 16 & 20 & 24 & 28 & 32 & 36 & 40 \\
\hline & 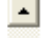 & 5 & & 10 & & 20 & & 30 & & 40 & & 50 \\
\hline & 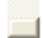 & 6 & 6 & 12 & 18 & 24 & 30 & 36 & 42 & 48 & 54 & 60 \\
\hline & -1 & 7 & & 14 & & 28 & & 42 & & 56 & & 70 \\
\hline TOTAL & & 8 & 8 & 16 & 24 & 32 & 40 & 48 & 56 & 64 & 72 & 80 \\
\hline & & 9 & & 18 & & 36 & & 54 & & 72 & & 90 \\
\hline & & 10 & 10 & 20 & 30 & 40 & 50 & 60 & 70 & 80 & 90 & 100 \\
\hline
\end{tabular}

Gambar 5. Tabel Habis Dibagi 2

Menghitung banyaknya bilangan yang habis dibagi 2 dilakukan dengan memberikan formula: =COUNT(C3:L12) ke sel A9. Formula tersebut memberikan luaran bahwa terdapat 75 bilangan genap di dalam tabel perkalian berukuran $10 \times 10$. Lumrah 
didengar pendapat bahwa separuh nilai dalam tabel perkalian $10 \times 10$ merupakan bilangan genap. Akan tetapi ketika dikonfrontasi melalui pemodelan spreadsheet diperoleh bahwa banyaknya bilangan genap adalah 75. Dalam range 1 sampai 10 ada 5 bilangan ganjil sehingga berpeluang 1 dari 4 bilangan dalam tabel perkalian berukuran $10 \times 10$ merupakan bilangan ganjil. Konsekuensinya 3 dari 4 bilangan merupakan bilangan genap. Dengan kata lain $75 \%$ nilai di dalam tabel perkalian berukuran $10 \times 10$ habis dibagi 2.

Generalisasi untuk tabel berukuran $n \times n$ serta faktor $f$ dapat dilakukan untuk dengan mengubah nilai $\mathrm{n}$ pada sel A3 dan faktor $f$ di sel A7. Gambar 6 dan 7 menunjukan bahwa pada tabel berukuran $2 k \times 2 k$ dan $(2 k-1) \times(2 k-1)$ terdapat $\mathrm{k}^{2}$ bilangan ganjil.

\begin{tabular}{|c|c|c|c|c|c|c|c|c|c|c|c|c|}
\hline A & B & & C & D & $\mathrm{E}$ & $\mathrm{F}$ & G & $\mathrm{H}$ & 1 & J & K & $\mathrm{L}$ \\
\hline & \multicolumn{12}{|c|}{ Multiplication Table } \\
\hline & \multirow[b]{2}{*}{ 스 } & & 1 & 2 & 3 & 4 & 5 & 6 & 7 & 8 & 9 & 10 \\
\hline & & 1 & 1 & & 3 & & 5 & & 7 & & 9 & \\
\hline & & 3 & 3 & & 9 & & 15 & & 21 & & 27 & \\
\hline & \multirow{5}{*}{$\underline{v}$} & 5 & 5 & & 15 & & 25 & & 35 & & 45 & \\
\hline & & 6 & & & & & & & & & & \\
\hline & & 7 & 7 & & 21 & & 35 & & 49 & & 63 & \\
\hline & & 8 & & & & & & & & & & \\
\hline & & 9 & 9 & & 27 & & 45 & & 63 & & 81 & \\
\hline & & 10 & & & & & & & & & & \\
\hline
\end{tabular}

Gambar 6. Banyak bilangan ganjil dalam tabel berukuran genap 


\begin{tabular}{|c|c|c|c|c|c|c|c|c|c|c|c|}
\hline A & \multicolumn{2}{|c|}{ B } & C & D & $E$ & $\mathrm{~F}$ & G & $\mathrm{H}$ & 1 & $\mathrm{~J}$ & K \\
\hline & \multicolumn{11}{|c|}{ Multiplication Table } \\
\hline & \multirow[b]{2}{*}{ 스 } & & 1 & 2 & 3 & 4 & 5 & 6 & 7 & 8 & $\mathrm{~g}$ \\
\hline & & \multirow{2}{*}{$\begin{array}{l}1 \\
2\end{array}$} & \multicolumn{2}{|l|}{1} & \multicolumn{2}{|l|}{3} & \multicolumn{2}{|c|}{5} & \multicolumn{2}{|c|}{7} & \multirow[t]{2}{*}{9} \\
\hline & 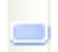 & & & & & & & & & & \\
\hline & & 3 & \multicolumn{2}{|c|}{3} & \multirow{2}{*}{\multicolumn{2}{|c|}{9}} & \multirow{2}{*}{\multicolumn{2}{|c|}{15}} & \multirow[t]{2}{*}{21} & & \multirow[t]{2}{*}{27} \\
\hline & \multirow[t]{6}{*}{$\underline{v}$} & 4 & & & & & & & & & \\
\hline & & 5 & \multirow[t]{2}{*}{5} & & \multirow{2}{*}{\multicolumn{2}{|c|}{15}} & \multirow[t]{2}{*}{25} & & \multirow[t]{2}{*}{35} & & \multirow[t]{2}{*}{45} \\
\hline & & 6 & & & & & & & & & \\
\hline & & 7 & \multirow{2}{*}{\multicolumn{2}{|c|}{7}} & \multirow{2}{*}{\multicolumn{2}{|c|}{21}} & \multirow[t]{2}{*}{35} & & \multirow[t]{2}{*}{49} & & \multirow[t]{2}{*}{63} \\
\hline & & 8 & & & & & & & & & \\
\hline & & 9 & 9 & & 27 & & 45 & & 63 & & 81 \\
\hline
\end{tabular}

Gambar 7. Banyak bilangan ganjil dalam tabel berukuran ganjil

\section{SIMPULAN dan SARAN}

Tabel perkalian yang dibangun menggunakan spreadsheet potensial untuk membelajarkan sejumlah konsep matematika. Konsep-konsep yang dimaksud diantaranya adalah: sifat komutatif, distributif perkalian terhadap penjumlahan, perkalian sebagai penjumlahan berulang, dan sifat habis dibagi. Di samping itu, lingkungan belajar dapat dirancang menyenangkan serta berpeluang memperdalam pemahaman guru maupun siswa terkait materi yang dibelajarkan. Konsekuensinya guru dituntut paham lebih mendalam konsep-konsep yang dibutuhkan dalam pengembangan lingkungan belajar sedemikan hingga selain menyenangkan juga mengarahkan siswa memahami konsep ketika digunakan dalam pembelajaran. Tentu tidak selalu mudah dikerjakan seperti pendapat Abramovich: "Although frustrated at first, I was very enthusiastic to learn that strategies could build upon one another to make mathematics easier. (Abramovich; 2004; 16). Dengan demikian tujuan mendasar yang lebih dari sekedar menyediakan lingkungan belajar yang menyenangkan dapat tercapai, yakni kontribusi pada menyiapkan guru matematika yang berkualitas yang dapat mendorong peningkatan pemahaman siswa. Kualifaikasi guru yang baik merupakan faktor krusial dalam mengungkap bakat potensial siswa secara menyeluruh melalui pewadahan kreativitas siswa yang dapat dituangkan melalui lingkungan belajar yang berkualitas.

Melihat potensi dukungan spreadsheet dalam meningkatkan kualitas lingkungan belajar maka disarankan kepada para praktisi matematika inovatif mencermati aktivitas- 
aktivitas lain-nya yang mesti dikerjakan siswa melalui tabel perkalian dalam upaya memahami konsep matematika. Lebih luas lagi perlu dipikirkan lingkungan belajar lainnya yang potensial untuk membelajarkan konsep-konsep matematika lainya sehingga siswa menyenangkan serta terarah dalam belajarnya.

\section{DAFTAR PUSTAKA}

Abramovich S., 2005, Uncovering Hidden Mathematics of the Multiplication Table Using Spreadsheets, Spreadsheets in Education (eJSiE), Volume 2.

Abramovich S., dan Brouwer P., 2003, Revealing hidden mathematics curriculum to pre-teachers using technology: The case of partitions, International Journal of Mathematical Education in Science and Technology, volume 34.

Bruner, JS, 1966, Toward a Theory of Instruction, Harvard University Press.

Conference Board of the Mathematical Sciences, 2001, The Mathematical Education of Teachers, Washington D.C.: Mathematical Association of America.

National Council of Teachers of Mathematics [NCTM], 2000, Principles and standards for school mathematics. Reston, VA: The National Council of Teachers of Mathematics.

Santos David A., 2007, Number Theory for Mathematical Contests.

Stewart, I., 1990, On the Shoulders of Giants, edited by LA Steen, Washington, DC: National Academy Press. 